\title{
ANÁLISIS COMPARATIVO DE LAS GALERÍAS DRENANTES TUNECINAS Y DEL SECTOR ORIENTAL Y SURORIENTAL ESPAÑOL. UN MODO DE CAPTACIÓN DE AGUAS SUBTERRÁNEAS EN LA CUENCA MEDITERRÁNEA ${ }^{1}$
}

\author{
Ghaleb Fansa \\ Miguel Antequera Fernández \\ Jorge Hermosilla Pla \\ Departamento de Geografía. Universidad de Valencia \\ ghaleb.fansa@uv.es, miguel.antequera@uv.es, jorge.hermosilla@uv.es
}

\section{RESUMEN}

En el ámbito mediterráneo la escasez e irregularidad de las precipitaciones fomenta el aprovechamiento de los acuíferos subterráneos para el abastecimiento y regadío. Las galerías drenantes, denominadas qanat ofoggara, tienen un papel destacado: extraen el agua del subsuelo mediante un túnel horizontal merced a la fuerza de la gravedad. Esta antigua técnica está presente en espacios áridos y semiáridos de Túnez y el sector oriental y suroriental de la península Ibérica. El objetivo de este artículo consiste en un análisis comparativo de las galerías de estos espacios.

Palabras clave: Galerías drenantes, qanat, patrimonio hidráulico, Túnez, España.

Fecha de recepción: marzo 2016.

Fecha de aceptación: marzo 2017.

1 Proyectos de investigación realizados sobre galerías drenantes (investigador principal: Jorge Hermosilla Pla)

- Foggara. Inventory, analysis and valorisation of traditional water techniques of european and saharan drainage tunnels, ICA3-CT-2002-10029-FOGGARA (2003-2007). Programa I+D de la Comisión Europea (V Programa Marco), Programa INCO-Cooperació amb Tercers Països.

- Estudio de las galerías drenantes españolas: selección y análisis de foggaras significativas (2007-2008). Ministerio de Medio Ambiente y del Medio Rural y Marino, Secretaría General de Planificación y Uso Sostenible del Agua.

- Las galerías drenantes: estudio, evaluación y revalorización de un elemento singular del patrimonio del agua en la cuenca hidrográfica del río Júcar (Teruel, Cuenca, Albacete y Valencia), HUM2007-62342 (2007-2011). Programa I+D+I del Ministerio de Ciencia e Innovación.

- Revalorización de las foggaras de la región del El Guettar: actuación en el conjunto de galerías y recuperación específica de una seleccionada, A/012134/07 (2008). Agencia Española de Cooperación Internacional para el Desarrollo (AECID). 


\section{ABSTRACT}

In mediterranean region, the low and erratic rainfall encourages the use of underground aquifers for water supply and irrigation. Drainage tunnels, called qanat or foggara have a prominent role in it: extract groundwater through a horizontal tunnel by the force of gravity. This ancient technique is present in arid and semiarid areas in Tunisia and in the eastern and southeastern sector of the Iberian Peninsula. The aim of this paper is a comparative analysis of the drainage tunnels of these spaces.

Keywords: Drainage tunnels, qanat, water heritage, Tunisia, Spain.

\section{INTRODUCCIÓN Y OBJETIVOS}

Las galerías drenantes, también conocidas con las denominaciones de qanat, foggara, karez, mkoula, mina, khettara, puquio... son referentes destacados del patrimonio hidráulico, debido a su grado de implantación en gran parte del mundo, como se pone de manifiesto en las obras de Wilkinson (1977), Goblot (1979), Kobori (1989), Lightfoot (1997) y Semsar Yazdi y Khaneiki (2010 y 2012), entre otros. En el ámbito mediterráneo las galerías drenantes poseen una notable importancia, ya que existen en la práctica totalidad de países, lo que se refleja en diversos estudios sobre esta temática.

En Túnez debemos citar por su interés los trabajos de El Amami (1984), Andrew (2009), Battesti (2012) y la comparativa que realizan Medgiche y Moussa (2014) sobre las galerías tunecinas y de Omán. Esta técnica cuenta con varios siglos de antigüedad, ya que está documentada desde el siglo VII a.C. Tanto en España como en Túnez existen galerías desde época romana, pero es en el país norteafricano donde contamos con alrededor de una quincena de ejemplos. Podemos citar entre ellas el Templo de las Aguas (Zaghouan), Ain Nasr Allah (Kairouan), Bir El Adine (Kairouan) o Ain Oued Kharroub (Sousse) (Gauckler, 1897-1912; Solignac, 1952). Las galerías son túneles horizontales excavados por debajo de la superficie terrestre con el objetivo de captar y extraer el agua de las capas freáticas, para que fluya al exterior por la acción de la gravedad. Se aprovechan de los acuíferos subterráneos más superficiales, al drenar la capa freática, sin sobreexplotar las reservas hídricas del acuífero. En el dominio climático mediterráneo, en el que se enmarca este estudio, existen sectores con una acusada escasez hídrica debido a unas precipitaciones escasas e irregulares. Ello da lugar a numerosos espacios áridos y semiáridos. La población allí asentada debe adaptarse a estas circunstancias mediante la utilización racional de los recursos. De ahí la importancia que adquieren las galerías drenantes para abastecer a los núcleos de población

- Puesta en valor del conjunto patrimonial de las foggaras de El Guettar (Túnez): itinerarios culturales y rehabilitación parcial de una foggara significativa (2009-2011). Comisión 0’7 de la Fundació General de la Universitat de València.

- Creación del centro de Estudios Mediterráneos de galerías de agua y paisajes asociados, D/026283/09 (2010-2011). Agencia Española para la Cooperación Internacional y el Desarrollo (AECID), Ministerio de Asuntos Exteriores y Cooperación.

- Proyecto “CEMGAP (Centro de Estudios Mediterráneos de Galerías de Agua y Paisajes Asociados)” (2011-2013). Agencia Española para la Cooperación Internacional y el Desarrollo (AECID), Ministerio de Asuntos Exteriores y Cooperación. 
y a los regadíos tradicionales, en periodos donde son prácticamente la única fuente de suministro (Castejón, 2014). En estos espacios el agua es un bien escaso y muy preciado.

En los últimos años diversos proyectos de investigación $\left({ }^{1}\right)$ nos han permitido tener un amplio conocimiento y experiencia sobre esta singular técnica de captación de aguas subterráneas en ambos territorios. De este modo podemos conocer sus principales características y la problemática que poseen actualmente.

Las galerías drenantes disponen de un elevado valor patrimonial, a consecuencia de diversos factores históricos, sociales, funcionales y, en la mayoría de ocasiones, paisajísticos. Las galerías y sus sistemas de regadío asociados son un factor de creación de paisaje y forman parte del patrimonio hidráulico. Los sistemas hidráulicos derivados de las galerías poseen un valor patrimonial que trasciende la propia obra arquitectónica, pues a través de los mismos se construyen unos paisajes culturales, que se constituyen en elementos de identidad para los territorios. Los elementos hidráulicos que forman la arquitectura del agua y los conocimientos para la gestión hídrica son importantes para la configuración de los paisajes mediterráneos. El futuro de las galerías drenantes depende en gran parte de su funcionamiento hídrico, y de que sigan extrayendo caudal al exterior, ya que el hecho de que estén activas facilita su conservación y mantenimiento. En las últimas décadas numerosas galerías han dejado de estar funcionales, e incluso han desaparecido, como ocurre con unas cuarenta situadas en los oasis del Sur. Las causas son diversas: factores climáticos; sobreexplotación de acuíferos; la crisis de los sistemas de regadío tradicionales, debido a factores como la inestabilidad de la agricultura como sector económico, el envejecimiento de los agricultores y su falta de relevo generacional, o los cambios en los usos del suelo que provocan su deterioro y, en ocasiones, su desaparición; y la falta de sensibilización de la sociedad y de sus representantes sobre el valor del patrimonio hidráulico.

El principal objetivo de este artículo consiste en la identificación, caracterización y análisis comparativo de las galerías drenantes de Túnez y del sector oriental y suroriental de la península Ibérica. Para ello se han establecido los siguientes objetivos específicos:

- Inventario, clasificación tipológica y cartografía de las galerías drenantes españolas y tunecinas.

- Confección de una base de datos espacial y realización de una cartografía automática con los principales resultados de la investigación.

- Análisis del funcionamiento hídrico, y del uso y gestión del agua de las galerías drenantes.

- Análisis del estado de conservación de las galerías y de los factores de crisis que influyen sobre las mismas y los sistemas de regadío que abastecen.

\section{METODOLOGÍA}

El área de estudio que comprende este artículo incluye la totalidad del territorio tunecino y, en España, el espacio formado por las demarcaciones de las Confederaciones Hidrográficas del Júcar, del Segura y las cuencas fluviales autóctonas de la provincia de Almería, en lo que constituye la franja mediterránea oriental y suroriental de la península ibérica. La metodología de trabajo que hemos desarrollado consta de varias fases en las que se realiza una distribución cronológica de las tareas en función de los objetivos y los resultados que se quieren obtener. Esta metodología, que hemos implementado en diversos 
proyectos, puede aplicarse sistemáticamente para cualquier territorio, y es la que hemos seguido tanto en el estudio de las galerías de E y el SE de España, como en las de Túnez.

La primera fase consiste en la consulta y análisis de las fuentes de información. En España se han consultado numerosas bibliotecas locales, provinciales y universitarias, mientras que en Túnez se han revisado los fondos de la Biblioteca Nacional, las bibliotecas universitarias y de algunos centros de investigación. Se realiza una consulta de documentación y artículos a través de Internet, lo que nos proporciona un amplio "corpus bibliográfico" sobre este tipo de captaciones. En España se han podido consultar diversos archivos Históricos (Provinciales y Municipales) y de otros organismos (Confederaciones Hidrográficas...), lo cual no ha sido posible en Túnez, ya que el acceso a esas fuentes es muy restringido. También se han realizado consultas a expertos como investigadores, cronistas locales, técnicos municipales, integrantes de las Comunidades de Regantes y usuarios. En España nos apoyamos en las fuentes cartográficas obtenidas en diversos organismos (Confederaciones Hidrográficas, Instituto Geológico y Minero de España -I.G.M.E.-, Diputaciones Provinciales...), donde se recogen listados de galerías georreferenciadas. El análisis de las fotografías aéreas, en ambos territorios, nos permitió la localización e identificación de varias captaciones, pese a que en Túnez dispusimos sólo de imágenes aéreas en sectores muy específicos del territorio. Asimismo se utilizaron fotografías recientes extraídas de la plataforma Google Earth. Los datos recopilados en esta fase permitieron la localización de numerosas referencias de galerías, lo que facilitó las tareas de identificación de las mismas en el posterior trabajo de campo.

En la segunda fase se efectúa el tratamiento de la información recogida en la fase precedente. Las tareas de las que se compone este periodo son:

a) Elaboración de un modelo de ficha de campo: permite la recogida de información en cada minado estudiado. Posee varias entradas generales como son la localización, contexto geográfico e hidrogeológico, análisis de la captación, funcionalidad y uso y otra información de interés.

b) Diseño de una base de datos espacial: posee una estructura similar a la ficha de campo, pero con algunas particularidades, ya que se añade un registro donde se pueden vincular textos, fotografías, planos, etc. Esta base permite sistematizar la información que se obtenga en el trabajo de campo.

c) Elaboración de una cartografía de identificación de las galerías según las referencias bibliográficas, cartográficas y documentales consultadas en la primera fase de la investigación. Esto permite localizar las galerías existentes y facilitar la visita a los minados que posteriormente pueden formar parte del catálogo. En Túnez se diseñó además un mapa con los oasis tradicionales existentes, para su posterior reconocimiento en el trabajo de campo, lo que posibilitó confirmar o descartar la existencia de galerías drenantes en los mismos.

La tercera fase está basada en el trabajo de campo y en el inventario y catálogo de galerías. En cada elemento catalogado se ha cumplimentado el modelo de ficha de campo. Se obtiene información mediante la observación directa de la captación, al tiempo que se realizan croquis, mediciones y fotografías. Se realiza un análisis interno y externo de 
la captación, además de entrevistarnos con sus gestores y usuarios. Existen galerías que se han localizado en la fase de trabajo de campo, por lo que la consulta de las fuentes de información se efectúa en una secuencia posterior. En esos casos se interrelacionan e invierten esas fases. En el sector oriental y suroriental español se han identificado unas 3.700 galerías. Al existir un número tan elevado surgió la necesidad de seleccionar, por lo que finalmente se han catalogado unas 300 galerías con los siguientes criterios: disponibilidad de información documental y cartográfica; accesibilidad al interior de la captación; estado de conservación; equilibrio territorial; relevancia histórico-social y clasificación tipológica. En Túnez realizamos un inventario completo de galerías, por lo que en total se estudian 125 captaciones.

En la cuarta fase se efectúan las tareas de análisis e interpretación de los resultados obtenidos en los anteriores periodos del estudio. Este periodo ha comprendido: 1- La elaboración de la información en la base de datos. Se trata de la confección y redacción de las fichas de las galerías, con la información que se ha recogido en las fases anteriores; 2- El análisis y la interpretación de los resultados. Es un periodo de razonamiento y reflexión sobre los temas tratados en la investigación; 3- La elaboración de figuras y cartografía automática (GIS), con los resultados gráficos de la investigación.

\section{RESULTADOS Y DISCUSIÓN}

\section{III.1. Factores medioambientales en la localización geográfica de las galerías}

Existen diversos factores medioambientales (el clima, la geomorfología, la hidrografía y la hidrogeología), que pueden influir en la localización de los minados, de forma individual y colectiva. El factor climático condiciona que las galerías se sitúen allí donde son necesarias, generalmente en los lugares donde no existen otras formas de acopio de caudal, como aguas superficiales permanentes o manantiales. Es por ello que nuestra hipótesis de partida fue que debían situarse en climas áridos y semiáridos, aun habiendo algunas excepciones. La influencia del clima en la distribución territorial de las galerías es por tanto una condición a gran escala, ya que suele actuar como un factor limitante y de modo indirecto. Si descendemos a una escala de análisis más detallada los factores geomorfológicos, topográficos, litológicos e hidrogeológicos tienen una influencia mayor en la localización concreta de cada minado. La disponibilidad de agua y de excedentes hídricos es un argumento fundamental para explicar la presencia de galerías. Esta afirmación se ve matizada por los factores hidrológicos (por la posibilidad de aportes hídricos alóctonos por medio de los cursos fluviales y la recarga de acuíferos aluviales a través de estos) e hidrogeológicos, (dada la existencia de acuíferos superficiales). La hidrogeología condiciona a pequeña escala, para cada galería y de forma independiente, ya que los minados se localizan allí donde se dan las condiciones idóneas para la existencia de un acuífero, para que pueda captar y transmitir el agua al exterior, en función de la capa impermeable y el tipo de materiales donde se encuentre excavada. Los factores geomorfológicos y la topografía condicionan el diseño de la galería y sus características constructivas internas (longitud, número de lumbreras, materiales de construcción...), lo que determina la estrategia que poseen para obtener el caudal. 
Cuadro 1

DISTRIBUCIÓN DE LAS GALERIAS EN FUNCIÓN DE LAS PRECIPITACIONES MEDIAS ANUALES (1971-2000)

\begin{tabular}{|c|c|c|c|c|}
\hline \multirow{2}{*}{ Precipitaciones (mm.) } & \multicolumn{2}{|c|}{ E y SE España } & \multicolumn{2}{c|}{ Túnez } \\
\cline { 2 - 5 } & $\mathrm{N}^{\mathrm{o}}$ & $\%$ & $\mathrm{~N}^{\mathrm{o}}$ & $\%$ \\
\hline$<100$ & 0 & 0 & 13 & $10^{\prime} 4$ \\
\hline $100-200$ & 5 & $1^{\prime} 7$ & 74 & $59^{\prime} 2$ \\
\hline $200-300$ & 46 & $15^{\prime} 4$ & 4 & $3^{\prime} 2$ \\
\hline $300-400$ & 103 & $34^{\prime} 6$ & 10 & 8 \\
\hline $400-500$ & 57 & $19^{\prime} 1$ & 6 & $4^{\prime} 8$ \\
\hline $500-600$ & 37 & $12^{\prime} 4$ & 12 & $9^{\prime} 6$ \\
\hline $600-700$ & 25 & $8^{\prime} 4$ & 6 & $4^{\prime} 8$ \\
\hline $700-800$ & 18 & $6^{\prime} 1$ & 0 & 0 \\
\hline $800-1.000$ & 7 & $2^{\prime} 3$ & 0 & 0 \\
\hline TOTAL & 298 & 100 & 125 & 100 \\
\hline
\end{tabular}

Fuente: elaboración propia a partir de Agencia Estatal de Meteorología (AEMET) (2011) y Henia (2008).

Figura 1

PRECIPITACIONES MEDIAS ANUALES (MM) Y LOCALIZACIÓN DE LAS GALERÍAS DRENANTES ANALIZADAS

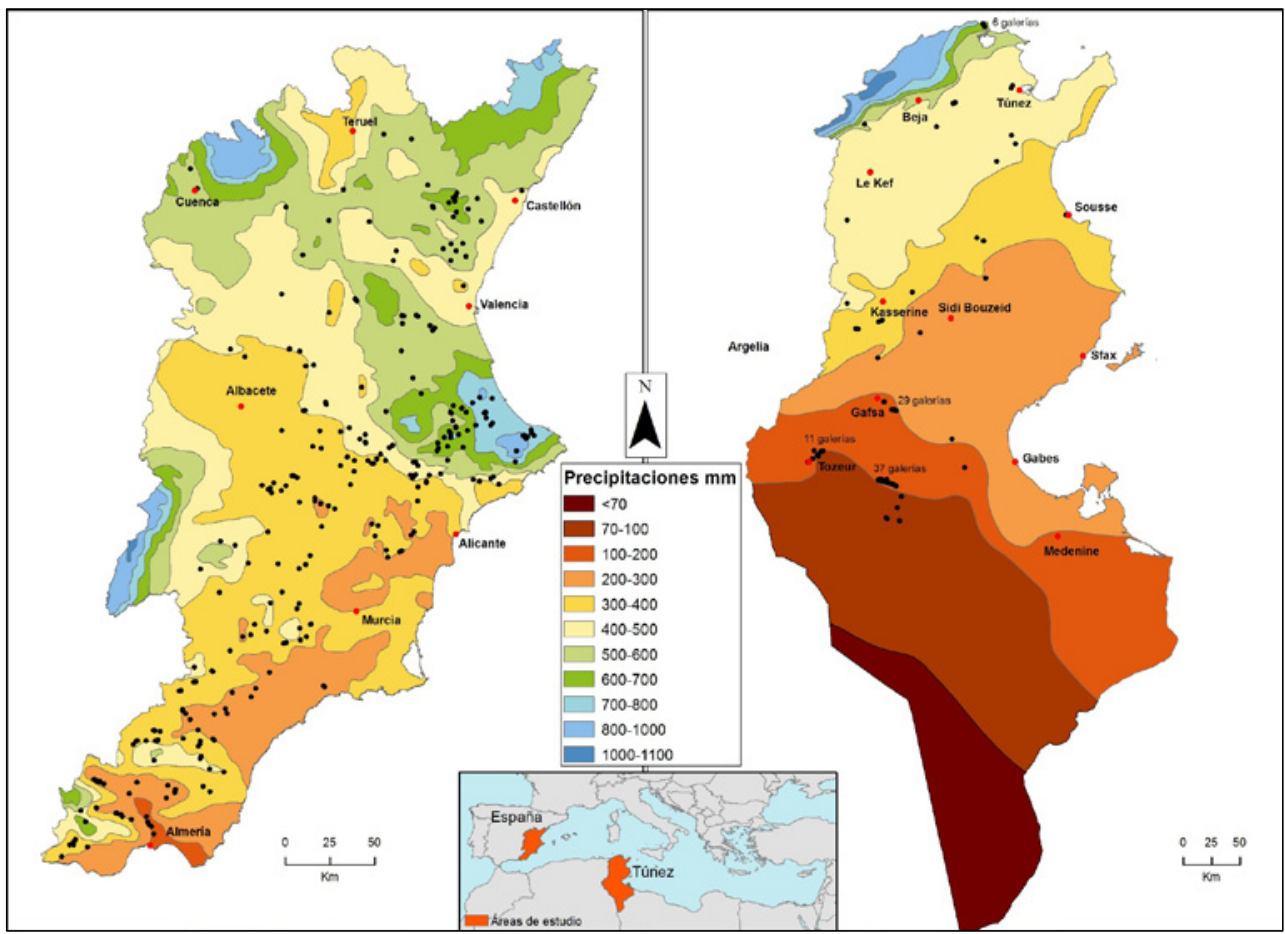

Fuente: elaboración propia a partir de AEMET (2011) y Henia (2008). 
Como indicábamos, el clima actúa como un factor limitante y a gran escala, no tanto como factor condicionante y a escala detallada. Las relaciones entre el clima y las galerías drenantes son más difusas y complejas que una simple correlación entre la precipitación media y el número total de captaciones. En el cuadro 1 se observa el número de galerías existentes según las isoyetas medias anuales. En Túnez el 70\% de los minados se localiza por debajo de la isoyeta de $200 \mathrm{~mm}$; destaca la franja entre 100 y $200 \mathrm{~mm}$, con el 59'2\%. Esta distribución se corresponde de forma aproximada con las galerías situadas en el sector meridional, en torno a algunos de los oasis tradicionales de las gobernaciones de Kebili, Tozeur y Gafsa. En el sector oriental y suroriental de España más de un tercio de los minados se ubican entre las isoyetas de 300 y $400 \mathrm{~mm}$. Si consultamos las isoyetas entre 200 y $400 \mathrm{~mm}$, observamos que la mitad de las captaciones están localizadas en ese espacio.

Estos datos confirman la hipótesis previa, según la cual las galerías se localizan básicamente en climas áridos y semiáridos. Esta hipótesis se cumple en términos generales, aunque existan algunas excepciones como en el sector sur de la provincia de Valencia (en la Safor y parte de la Vall d'Albaida) y en el norte de la de Alicante (en la Marina Alta). Sólo el 17\% se encuentran más allá de la isoyeta de los $600 \mathrm{~mm}$. En Túnez no existe ninguna galería ubicada en lugares con una pluviometría superior a los $700 \mathrm{~mm}$, mientras que en el sector oriental y suroriental de España no se ha catalogado ninguna en los sectores con una isoyeta superior a los $1.000 \mathrm{~mm}$ de precipitación.

\section{III.2. Clasificación tipológica de galerías}

Los qanats son el sistema original de captación de aguas subterráneas a partir del uso de galerías drenantes. Quizás por ello el resto de galerías no ha recibido por parte de los autores el mismo interés, debido a la escasez de referencias que las analicen en detalle. El investigador israelí Ron (1995) indica que los qanats poseen una amplia literatura por parte de los investigadores, mientras que las minas (spring tunnels) son descritas de modo muy superficial y existen insuficientes estudios sobre las mismas. Una apreciación similar realizan Bertrand y Sánchez Viciana (2009), donde indican que los sistemas de captación de aguas subterráneas mediante cimbras y tajeas no han recibido la atención que precisan.

En la bibliografía no existen excesivas clasificaciones referidas a las diferentes tipologías de galerías existentes. Todo lo contrario, pues sorprende por su escasez. En ese sentido hallamos varios argumentos: a) En los lugares de origen y gran concentración de qanats puede que no existan otras tipologías distintas. b) Varios autores consideran sólo los qanats como su objeto de estudio, lo que da lugar a que sus trabajos y clasificaciones se centren exclusivamente en esta forma de captación, sin que analicen las minas ni las captaciones situadas en el subálveo de las terrazas o lechos fluviales. c) La clasificación tipológica supone una gran complejidad, ya que conlleva dificultades para poder realizarla (combinación de soluciones técnicas y arquitectónicas en una misma galería; emplazamiento en ambientes geográficos heterogéneos; alteraciones sobre el minado original mediante las intervenciones en tareas de ampliación, mantenimiento, o limpieza; ausencia de documentación acerca de su diseño y construcción...).

La clasificación tipológica es un tema abierto, ya que al analizar un mayor número de galerías las tipologías y subtipos pueden aumentar y modificarse. En la mayoría de clasifi- 
caciones suelen detallarse los principales tipos, y apenas se hace mención a sus variantes. Los investigadores iraníes Semsar Yazdi y Khaneiki (2010) efectúan varias clasificaciones de qanats en función de diversos parámetros, pero sin tener en cuenta otras tipologías de galerías. En ocasiones sólo se especifican los grandes tipos existentes, sin realizar una clasificación pormenorizada que recoja las diferentes variantes y subtipos. Así ocurre en las de Cressier (1989), Palerm Viqueira (2004) y en la de Gómez Espín, Gil Meseguer y Martínez Medina (2007, 2011 y 2012). Otros autores realizan ensayos de clasificación pero basados exclusivamente en factores hidrogeológicos (Kobori, 1976) o en el tipo de materiales (Barón y Carbonero, 1987).

En los trabajos efectuados por el grupo de investigación ESTEPA desde el año 2004 hemos realizado varias clasificaciones mediante la combinación de diversos criterios, lo que da lugar a una amplia variedad tipológica de galerías. Esta primera propuesta se amplía en años posteriores (Hermosilla y Antequera, 2006 y 2008). En la tesis doctoral de Miguel Antequera (2015) se elabora un ensayo de clasificación, heredero de los anteriores, que constituye la base que aplicamos en este estudio. Nuestra propuesta de tipología de galerías se efectúa en base a tres criterios, complementarios entre sí, lo que nos permite realizar varias clasificaciones. Estos criterios son: el origen de las aguas captadas; sus características constructivas y funcionales, lo que determina su tipología; y el ambiente geográfico en el que se ubican (montaña, espacios intermedios y cursos y terrazas fluviales). Estas clasificaciones permiten que se pueda realizar un ensayo de tipificación, consecuencia de aunar los tres criterios.

Para distinguir el origen del agua captada las galerías se agrupan en categorías, según el tipo de acuífero del que se abastecen: a) Aguas subterráneas: proceden de los acuíferos formados por fisuración o estratificación, con independencia de que sean colgados, locales o regionales. También se incluyen los acuíferos terciarios y los detríticos cuaternarios situados en un ambiente diferente al de los cursos y terrazas fluviales. b) Aguas subálveas y detríticas aluviales cuaternarias: se incluyen los acuíferos subálveos, que son los que se aprovechan de la circulación subsuperficial existente en un cauce, y las aguas procedentes de los acuíferos detríticos aluviales cuaternarios, en los casos en que la galería tenga una circulación longitudinal a través de su lecho. c) Origen mixto: combinan las aguas subterráneas con las subálveas. Ambos aportes tienen una influencia destacada en la producción hídrica de la captación sin que se pueda determinar con precisión cual tiene mayor incidencia en el caudal; d) Aguas subterráneas y superficiales: existe un único caso donde se produce una conjunción entre las aguas subterráneas y superficiales (Fuente de los Molinos del río Aguas, Sorbas, Almería).

La clasificación efectuada según el origen de las aguas es muy oportuna, ya que existe una correspondencia entre el origen del agua y las tipologías que suelen abastecerse con este tipo de acuíferos. En el sector oriental y suroriental de la península Ibérica la correlación es del 94\%, mientras que en Túnez alcanza el 96\% de los minados, por lo que esta clasificación es muy efectiva. En el sector oriental y suroriental español casi tres cuartas partes de los minados se aprovechan de las aguas subterráneas, mientras que en Túnez este porcentaje aumenta hasta el 94'4\%, debido a la existencia mayoritaria de la tipología qanat. En la parte analizada de España el 23'8\% de las galerías se abastecen de las aguas subálveas o detríticas cuaternarias, debido a que se corresponden con tipologías con un número menor de ejemplos, situadas en cauces y terrazas fluviales, generalmente en las provincias de Almería y Murcia. En Túnez sólo el 5’6\% de las galerías captan este tipo de acuíferos. 
Figura 2

ENSAYO DE CLASIFICACIÓN TIPOLÓGICA DE LAS GALERIASS DRENANTES CATALOGADAS

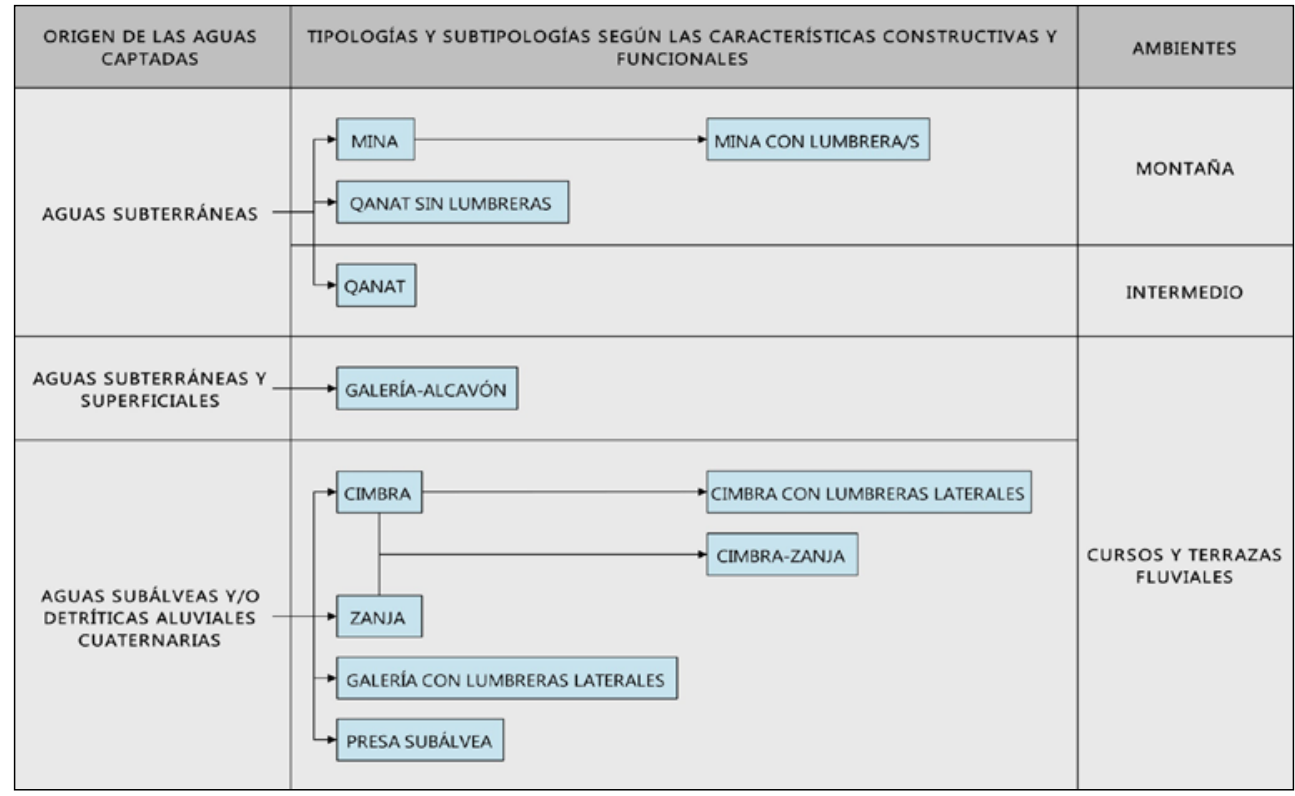

Fuente: elaboración propia.

Cuadro 2

ORIGEN DE LAS AGUAS CAPTADAS EN LAS GALERÍAS CATALOGADAS

\begin{tabular}{|c|c|c|c|c|}
\hline \multirow{2}{*}{ Origen del agua } & \multicolumn{2}{|c|}{ E-SE España } & \multicolumn{2}{c|}{ Túnez } \\
\cline { 2 - 5 } & $\mathrm{N}^{\mathrm{o}}$ & $\%$ & $\mathrm{~N}^{\mathrm{o}}$ & $\%$ \\
\hline Subterránea & 218 & 73,2 & 118 & 94,4 \\
\hline Subálveas y/o detríticas aluviales cuaternarias & 71 & 23,8 & 7 & 5,6 \\
\hline Subterráneas y subálveas & 8 & 2,7 & 0 & 0 \\
\hline Subterráneas y superficiales & 1 & 0,3 & 0 & 0 \\
\hline TOTAL & 298 & 100 & 125 & 100 \\
\hline
\end{tabular}

Fuente: elaboración propia.

Las características constructivas y funcionales permiten fijar los tipos y subtipos de galerías existentes, ya que cada una de ellas se define en función del modo de excavación y la solución técnica empleada para el acopio del caudal. A consecuencia del mestizaje tecnológico, en una misma galería pueden existir técnicas de construcción correspondientes a diferentes tipologías. Del ensayo de clasificación propuesto por Antequera (2015) realizamos algunas agrupaciones, lo que da lugar a 10 tipos de galerías en el sector oriental y suroriental de la península Ibérica, de los que sólo 7 están presentes en Túnez. Las tres tipologías que existen en España, y no en Túnez, forman un porcentaje muy reducido de las galerías estudiadas (10 de 298 galerías). Una 
circunstancia que es debida a que se trata de subtipos de captaciones excepcionales. A continuación enumeramos las tipologías y sus características constructivas y funcionales:

- Mina: excavaciones subterráneas a partir de la profundización de un manantial o una surgencia. Este tipo de captación posee una escasa longitud, aunque existen excepciones en los casos de galerías más modernas, perforadas en el último siglo, con modernas técnicas mineras. No disponen de pozo madre ni de lumbreras. Podemos citar la Fuente Larga (Vall de Almonacid, Castellón) y la galería de Ain El Mahjuba (Le Kef).

- Mina con lumbreras: se originan con una excavación subterránea a partir de un manantial o surgencia. No poseen pozo madre. En su trazado cuenta con una o dos lumbreras verticales intermedias. Destacamos la Mina de la Huerta Nueva (Buñol, Valencia) y la de Ain el Menzel (Beja).

- Qanat sin lumbreras: el origen de la captación consiste en la excavación subterránea de un pozo madre hasta alcanzar el nivel freático. La perforación de la galería se realiza desde la bocamina hasta el pozo madre. No dispone de lumbreras verticales. Esta tipología es difícil de clasificar debido a que el pozo madre que da origen a la captación con frecuencia ha sido cegado. No se ha localizado ninguna en territorio tunecino y los únicos ejemplos que disponemos están en el sector E-SE de España. Uno de los más significativos es la Mina Segunda de la Umbría (Ontur, Albacete), debido a que no se ha cegado el pozo madre.

- Qanat: son el sistema original de captación de aguas subterráneas a partir de la utilización de galerías drenantes. Su origen consiste en la construcción de un pozo madre hasta alcanzar el acuífero. Se excava desde la bocamina hasta el pozo madre. Posee varias lumbreras verticales o respiraderos en su trazado. Estos registros se utilizaban como entradas a la captación y como vías de iluminación y aireación, además de su uso para la extracción de los escombros durante la construcción de la galería. Dos ejemplos significativos son los de la Fuente de Santa María (Ibi, Alicante) y el de Ain Nasr Allh (Kairouan).

- Cimbra y cimbra con lumbreras laterales: captan las aguas subálveas y/o detríticas aluviales cuaternarias y suelen situarse en un ambiente de cursos y terrazas fluviales. La galería se excava en el curso de agua de forma subterránea, en dirección contraria a la de la escorrentía y con un desnivel muy escaso. Las aguas se infiltran desde la superficie y rezuman a través del techo de la captación y de sus hastiales, y sólo la parte baja de la galería está impermeabilizada con cal hidráulica. No disponen de pozo madre y se excavan de forma subterránea desde la bocamina hasta la cabeza. Poseen varias lumbreras verticales o respiraderos. Pueden señalarse tanto la Mina de Aguas del Paraíso (Caudete, Albacete), como la galería de Ain Oued Sbeitla (Kasserine). La cimbra con lumbreras laterales u horizontales posee las mismas características que la cimbra, pero con la particularidad de que esas lumbreras laterales pueden tener la doble función de ser el inicio de una acequia de riego, y servir como un acceso al interior de la captación para las labores de construcción, y posteriormente de reparación, limpieza y mantenimiento.

- Zanja: no utilizan una técnica minera de excavación, ya que es suficiente la perforación de una zanja o trinchera a cielo abierto en los materiales aluviales poco cohesionados. Posteriormente se cubre con losas de piedra planas y se recubre con los materiales removidos en la excavación. No dispone de lumbreras verticales por lo que es difícil encontrarla sin alteraciones. Se excava desde la bocamina hasta la cabeza de la captación. Cuando es 
necesaria su limpieza se abre un orificio en los materiales del lecho de la rambla y se retira alguna de las losas que forman el dintel del techo. Debemos citar la Fuente de la Montalbana (Torralba del Pinar, Castellón) y Ain Ben Ghilouf (Gabes).

- Cimbra-zanja: combina la excavación de una zanja a cielo abierto con la excavación subterránea con técnicas mineras. Dispone de varias lumbreras verticales o respiraderos. Se aprovechan de las aguas subálveas y/o detríticas aluviales cuaternarias. En el tramo más cercano a la bocamina la captación es una zanja, recubierta con lajas de piedra. Conforme nos adentramos en el minado hacia su cabecera cuenta con varias lumbreras o pozos de aireación y su profundidad aumenta de forma considerable. Dos ejemplos significativos son los de la Zanja del Gadil (Armuña de Almanzora, Almería) y Ain Oued El Kiss (Kasserine).

- Presa subálvea: su principal característica consiste en que esta captación dispone de una presa subálvea situada a varios metros de profundidad con respecto al cauce fluvial. Su construcción debe producirse en un lugar donde las condiciones hidrogeológicas sean las idóneas. El cauce donde se asienta debe poseer una acumulación destacada de arenas, cantos y gravas que recubran el lecho, y disponer además de un nivel impermeable de base en un lugar estrecho que encierre el río o la rambla. Este depósito posee varios metros de espesor, decenas de metros de anchura y cientos de metros de longitud, lo que constituye una especie de vaso de embalse subterráneo ante la presa enterrada, lo que permite captar la infiltración del lecho fluvial y recuperar gran parte del flujo subsuperficial que circula por el subálveo (Gil Meseguer et al., 2011). La galería se realiza mediante la perforación de una zanja en trinchera, a cielo abierto. El agua se capta mediante unos orificios llamados mechinales o troneras situados en la pared anterior de la galería, que es la más cercana al flujo subsuperficial que circula por la rambla. La pared contraria, la que forma parte de la presa, está impermeabilizada y revestida con cal hidráulica para evitar pérdidas por filtraciones. En su trazado existen varias lumbreras verticales, pero sin pozo madre, ya que se excava desde la bocamina hasta la cabeza. Las más destacadas son el Caño Viejo y Contracaño (Puerto Lumbreras, Murcia) y las galerías de Oued Bou Haya (Kasserine). Las presas subálveas pueden ser de dos tipos: a) Antepuesta: la presa subálvea lleva antepuesta y adosada una galería, por la que se conduce el agua al exterior. La presa es de un sólo muro y se construye de forma oblicua al flujo de la corriente y al sentido de la rambla. b) Inscrita: la presa subálvea está compuesta por dos muros de contención, paralelos entre sí y oblicuos al cauce, entre los cuales se inserta la galería. El muro posterior está revocado para evitar las filtraciones y el anterior se hizo permeable para que la galería inscrita pudiera captar la circulación subálvea. En las presas subálveas inscritas la galería forma parte de la presa.

- Galería con lumbreras laterales: suelen estar situadas en un ambiente de terraza fluvial, aunque en su construcción emplean exclusivamente técnicas de excavación subterránea. No disponen de pozo madre ni de lumbreras verticales. Poseen varias lumbreras laterales, ya que a consecuencia del espesor de los sedimentos de la terraza fluvial es más sencillo alcanzar la galería con una excavación horizontal de unos pocos metros, que con lumbreras verticales mucho más profundas. Estas lumbreras horizontales se emplean para servir como acceso a la captación en las tareas de construcción y mantenimiento. En ocasiones también poseen la función de extraer el caudal al exterior mediante una acequia que lo conduce a los lugares de utilización. No se ha localizado ninguna en Túnez, mientras que en el sector oriental y suroriental español se puede citar la Galería Segunda de les Fontetes (Quatretonda, Valencia). 


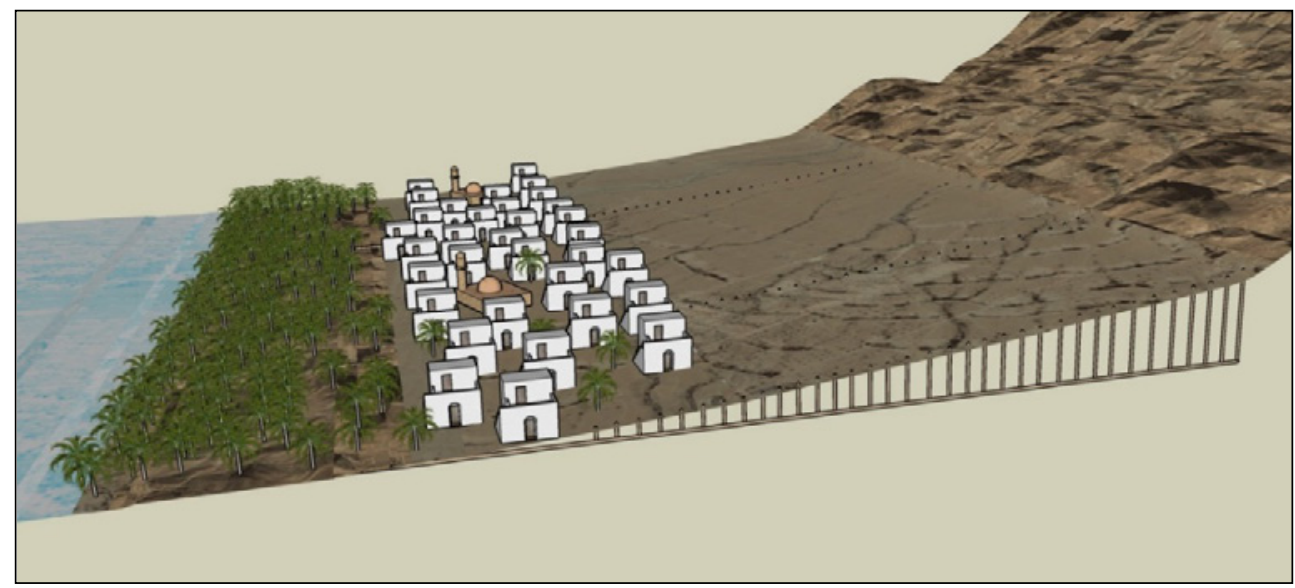

Fuente: elaboración propia.

- Galería-alcavón: es un tipo excepcional de galería que se aprovecha de una combinación de aguas subterráneas y superficiales. No posee lumbreras verticales, pero sí varias lumbreras laterales u horizontales. En el exterior dispone de un azud que suministra un caudal suplementario a la captación. El único caso de este tipo de captación lo encontramos en la Fuente de los Molinos del Río Aguas (Sorbas, Almería).

TIPOLOGÍAS DE GALERÍAS, EN FUNCIÓN DE SUS CARACTERISTIICAS CONSTRUCTIVAS Y FUNCIONALES.

\begin{tabular}{|c|c|c|c|c|}
\hline \multirow{2}{*}{ Tipologías } & \multicolumn{2}{|c|}{$\mathrm{N}^{\circ}$} & \multicolumn{2}{c|}{$\%$} \\
\cline { 2 - 5 } & E-SE España & Túnez & E-SE España & Túnez \\
\hline Mina & 86 & 13 & 28,9 & 10,4 \\
\hline Mina con lumbrera & 19 & 3 & 6,4 & 2,4 \\
\hline Qanat sin lumbreras & 6 & 0 & 2 & 0 \\
\hline Qanat & 110 & 97 & 36,9 & 77,6 \\
\hline Galería-alcavón & 1 & 0 & 0,3 & 0 \\
\hline Cimbra y Cimbra con lumbreras laterales & 52 & 5 & 17,4 & 4 \\
\hline Zanja & 2 & 3 & 0,7 & 2,4 \\
\hline Cimbra-zanja & 15 & 3 & 5 & 2,4 \\
\hline Presa subálvea & 4 & 1 & 1,3 & 0,8 \\
\hline Galerías con lumbreras laterales & 3 & 0 & 1 & 0 \\
\hline TOTAL & 298 & 125 & 100 & 100 \\
\hline
\end{tabular}

Fuente: elaboración propia. 
Como se observa en el cuadro 3 la tipología del qanat, situada generalmente en ambientes intermedios como los piedemontes, glacis y conos de deyección, es la más abundante tanto en los minados españoles, donde suponen más de un tercio del total (36’9\%), como sobre todo en los tunecinos, donde alcanza el $77^{\prime} 6 \%$. Esta cifra tan elevada para el país norteafricano se debe al gran número de galerías existentes en los piedemontes situados entre las cadenas montañosas del sur y los bordes de los chotts o sebhkas. La existencia de numerosos qanats en esos espacios posibilitó la existencia de oasis tradicionales como los de Souk el Ahad y Mansoura en Kebili, El Guettar en Gafsa y Degueche en Tozeur. En el área analizada del territorio español los qanats, aunque están presentes en la mayoría de zonas, se emplazan sobre todo en el sector septentrional de la provincia de Murcia, en los municipios de Yecla y Jumilla y en extremo suroriental de la provincia de Albacete, en localidades como Almansa, Caudete o Tobarra. Esta localización se debe a que en estos territorios se dan las condiciones topográficas e hidrogeológicas idóneas, con numerosos ambientes intermedios o de transición, donde predominan los piedemontes y los diferentes tipos de glacis.

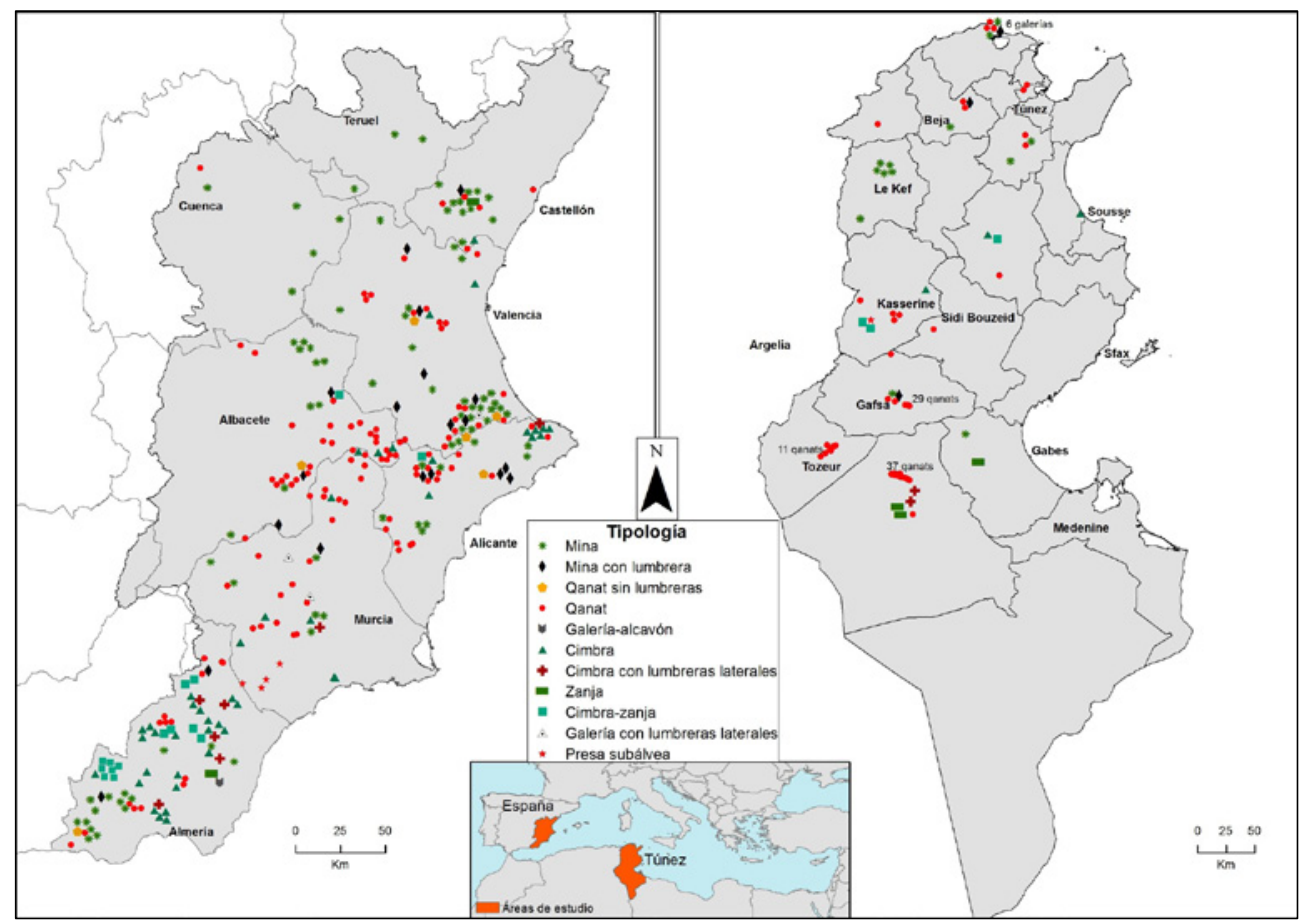

Fuente: elaboración propia.

Las minas, que son el tipo de galería más habitual en los ambientes de montaña, suponen el 28’9\% en el sector oriental y suroriental de la península Ibérica, mientras que en Túnez 
representa sólo el 10`4\%. Aunque esta tipología se sitúa en la totalidad del área analizada en España, es más frecuente encontrarla en las zonas más septentrionales, en las provincias de Cuenca, Castellón y Valencia, donde representan un porcentaje destacado con respecto al total $\left(83^{\prime} 3 \%, 58^{\prime} 8 \%\right.$ y $41^{\prime} 4 \%$, respectivamente).

El grupo de tipologías de galerías que suele ubicarse en cursos y terrazas fluviales se compone de 77 minados en el sector español y de 12 en Túnez, lo que supone un 25'8\% y un 9'6\% respectivamente. La tipología más destacada en estos espacios es la de cimbra, que representa el 17'4\% en las galerías analizadas en España. Se localiza en su mayor parte en el sector más meridional del área de estudio, formado por la provincia de Almería y el sur de la de Murcia. En este espacio, a consecuencia de la escasez e irregularidad de las precipitaciones y de la inexistencia de cursos fluviales permanentes, se aprovechan de la circulación subálvea de ríos-rambla como el Andarax, Almanzora, Guadalentín y rambla de Nogalte. Sin embargo hacia el Norte este tipo de captaciones escasea e incluso no hay en algunas zonas.

Una vez analizado el origen de las aguas que capta cada minado y la tipología constructiva y funcional que poseen, un tercer criterio complementario de clasificación de galerías es el ambiente geográfico donde están ubicadas. Se agrupan en tres grandes ambientes geomorfológicos:

a) Contextos ambientales de montaña: incluyen los ambientes de ladera, base de ladera y plataformas, ya sean detríticas, tabulares o calcáreas. Las tipologías y subtipos resultantes son las de mina, mina con lumbrera y qanat sin lumbreras.

b) Contextos ambientales intermedios o de transición: en esta categoría se agrupan los piedemontes (ya sean abarrancados, coluviales, sensu lato...), los glacis (de acumulación, de erosión, con cubierta, abarrancados...) y los conos de deyección. La tipología habitual en este tipo de ambiente es la de los qanat.

c) Contextos ambientales de cursos y terrazas fluviales: aquí se integran los lechos y terrazas fluviales, las vaguadas y los barrancos. En estos ambientes se corresponden las tipologías de cimbra, cimbra con lumbreras laterales, zanja, cimbra-zanja, galería-alcavón, galería con lumbreras laterales y presa subálvea. Para determinar con precisión la ubicación en uno u otro ambiente, además de tener en cuenta sus características geomorfológicas, nos apoyamos en la pendiente existente, para lo cual seguimos la clasificación propuesta por Young (1974): en los ambientes de montaña la pendiente es superior a los $10^{\circ} \mathrm{o} 12^{\circ}$; en los contextos ambientales intermedios o de transición como piedemontes, glacis y conos de deyección la pendiente oscila entre $\operatorname{los} 2^{\circ}$ y $3^{\circ}$ y los $10^{\circ}$ o $12^{\circ}$; en los ambientes de llanura y cursos y terrazas fluviales la pendiente es inferior a $\operatorname{los} 2^{\circ}$ o $3^{\circ}$.

Atendiendo a estos criterios no todas las galerías están situadas en el ambiente geográfico que se les presupone, en función de sus técnicas constructivas y funcionales, por lo que en algunos casos se hallan descontextualizadas y fuera del ámbito donde suelen encontrarse habitualmente. Una misma galería puede participar de dos ámbitos geomorfológicos diferentes, y en ocasiones se combina el ambiente de la tipología a la que pertenece con otro ajeno a la misma. 
El cuadro 4 muestra el número de galerías pertenecientes a cada uno de los grandes ambientes geográficos, en función de sus características constructivas y funcionales, y se detalla para cada una de las tipologías aquellas que se sitúan en el ambiente geográfico que les corresponde teóricamente o bien quedan fuera del mismo. También se especifican aquellas galerías situadas en dos tipos de ambientes distintos, cuando uno de ellos es el propio de su tipología y el otro no es el habitual. En el área oriental y suroriental de la península Ibérica más del $70 \%$ de las galerías se localizan en el ambiente geográfico que les corresponde en función de su tipología constructiva y funcional, mientras que en Túnez ese porcentaje se incrementa hasta el $87 \%$, lo cual demuestra la eficacia de esta clasificación. Fuera de su ambiente habitual se encuentra el $22 \%$ de las galerías en el sector analizado en España y el $11 \%$ en Túnez. Son escasos los ejemplos donde, en un mismo minado, se produce la alternancia de un contexto ambiental propio y otro ajeno (7\% en el en sector oriental y suroriental español y el 1'6\% en el tunecino).

Cuadro 4

CONTEXTOS GEOGRÁFICOS AMBIENTALES POR TIPOLOGÍAS CONSTRUCTIVAS Y FUNCIONALES

\begin{tabular}{|c|c|c|c|c|c|c|c|c|c|c|c|c|c|}
\hline \multirow{3}{*}{ 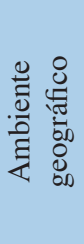 } & \multirow{3}{*}{$\begin{array}{l}\text { Tipologías de } \\
\text { galerías }\end{array}$} & \multicolumn{4}{|c|}{$\begin{array}{c}\text { Contexto ambiental } \\
\text { propio }\end{array}$} & \multicolumn{4}{|c|}{$\begin{array}{c}\text { Fuera de su ambiente } \\
\text { habitual }\end{array}$} & \multicolumn{4}{|c|}{$\begin{array}{c}\text { Alternancia } \\
\text { contexto propio y } \\
\text { ajeno }\end{array}$} \\
\hline & & \multicolumn{2}{|c|}{$\begin{array}{l}\text { E-SE } \\
\text { España }\end{array}$} & \multicolumn{2}{|c|}{ Túnez } & \multicolumn{2}{|c|}{$\begin{array}{c}\text { E-SE } \\
\text { España }\end{array}$} & \multicolumn{2}{|c|}{ Túnez } & \multicolumn{2}{|c|}{$\begin{array}{c}\text { E-SE } \\
\text { España }\end{array}$} & \multicolumn{2}{|c|}{ Túnez } \\
\hline & & $\mathrm{N}^{\circ}$ & $\%$ & $\mathrm{~N}^{\circ}$ & $\%$ & $\mathrm{~N}^{\mathrm{o}}$ & $\%$ & $\mathrm{~N}^{\circ}$ & $\%$ & $\mathrm{~N}^{\mathrm{o}}$ & $\%$ & $\mathrm{~N}^{\circ}$ & $\%$ \\
\hline \multirow{3}{*}{ 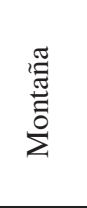 } & Mina & 66 & $76^{\prime} 7$ & 10 & $76 ’ 9$ & 16 & $18^{\prime} 6$ & 3 & $23{ }^{\prime} 1$ & 4 & $4 ’ 7$ & 0 & 0 \\
\hline & $\begin{array}{l}\text { Mina con } \\
\text { lumbrera }\end{array}$ & 13 & $68^{\prime} 4$ & 2 & $66^{\prime} 6$ & 5 & $26 ’ 3$ & 1 & $33^{\prime} 3$ & 1 & $5^{\prime} 3$ & 0 & 0 \\
\hline & $\begin{array}{l}\text { Qanat sin } \\
\text { lumbreras }\end{array}$ & 3 & 50 & 0 & 0 & 3 & 50 & 0 & 0 & 0 & 0 & 0 & 0 \\
\hline 咅: & Qanat & 66 & 60 & 87 & $89 ’ 7$ & 36 & $32 ’ 7$ & $9(*)$ & $9 ’ 3$ & 8 & $7 ’ 3$ & 1 & 1 \\
\hline \multirow{6}{*}{ 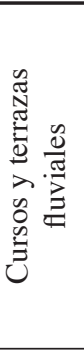 } & Galería-alcavón & 0 & 0 & 0 & 0 & 0 & 0 & 0 & 0 & 1 & 100 & 0 & 0 \\
\hline & $\begin{array}{l}\text { Cimbra / Cimbra } \\
\text { lumbreras laterales }\end{array}$ & 42 & $80 ’ 7$ & $4(*)$ & 80 & 3 & $5^{\prime} 8$ & 0 & 0 & 7 & $13 ' 5$ & 1 & 20 \\
\hline & Zanja & 1 & 50 & $2(*)$ & $66^{\prime} 6$ & 1 & 50 & 1 & $33 ’ 3$ & 0 & 0 & 0 & 0 \\
\hline & Cimbra-zanja & 15 & 100 & 3 & 100 & 0 & 0 & 0 & 0 & 0 & 0 & 0 & 0 \\
\hline & $\begin{array}{c}\text { Galería lumbreras } \\
\text { laterales }\end{array}$ & 1 & $33^{\prime} 3$ & 0 & 0 & 2 & $66^{\prime} 6$ & 0 & 0 & 0 & 0 & 0 & 0 \\
\hline & Presa subálvea & 4 & 100 & 1 & 100 & 0 & 0 & 0 & 0 & 0 & 0 & 0 & 0 \\
\hline & TOTAL & 211 & $70^{\prime} 8$ & 109 & $87 ’ 2$ & 66 & $22 ' 1$ & 14 & $11{ }^{\prime} 2$ & 21 & $7 ' 1$ & 2 & $1 ' 6$ \\
\hline
\end{tabular}

(*) Existen áreas llanas situadas en los bordes del Sahara, que por contexto geomorfológico se han incluido en ese ambiente, al tener una pendiente inferior a $\operatorname{los} 2^{\circ}$ o $3^{\circ}$. Existen 2 ejemplos en las cimbras con lumbreras laterales, 2 entre las zanjas y una entre los qanats.

Fuente: elaboración propia. 
El análisis de los resultados en función de los grandes ambientes geográficos indica que esta clasificación es bastante eficaz para las tipologías situadas en cursos y terrazas fluviales y para las emplazadas en ambientes de montaña. Tanto en Túnez como en España las galerías ubicadas en su ambiente propio superan el $80 \%$ en los espacios de cursos y terrazas fluviales (con las tipologías de cimbra, zanja, cimbra-zanja, presa subálvea...) y se sitúan en torno al $75 \%$ en las áreas de montaña (con la tipologías de mina, mina con lumbreras y qanat sin lumbreras). La mayor diferencia entre España y Túnez radica en las tipologías de galerías correspondientes a los espacios intermedios, donde la disparidad entre ambas áreas es manifiesta. En el sector oriental y suroriental español sólo el $60 \%$ de los qanats están situados en un ambiente intermedio, mientras que un tercio de los mismos están en un contexto ambiental ajeno al que le correspondería, por lo que se encuentran captaciones descontextualizadas en función de su teórica localización si nos atenemos a sus características constructivas. Se produce por varias razones: la existencia de un mestizaje tecnológico, ya que suelen emplearse técnicas y modos de construcción pertenecientes a una tipología y un ambiente concreto en galerías situadas en un ambiente distinto al habitual; la construcción de un tipo u otro de galería está condicionado por el contexto hidrogeológico y las características del acuífero que se quiere drenar. Sin embargo en Túnez la mayor parte de los qanats (90\%) están ubicados en el contexto que les corresponde, como son los ambientes intermedios o de transición. La mayoría se localiza en los piedemontes de las cadenas montañosas del sur de Túnez como el Djebel Orbata en El Guettar (Gafsa); Djebel Tebaga, en Souk el Ahad y Mansoura (Kebili); y la Dorsal de Chareb en Degeche (Tozeur).

\section{III.3. Funcionamiento hídrico, uso y gestión del agua}

Quizás el parámetro fundamental para medir la "salud ambiental" de una galería sea el que siga realizando la función para la que fue concebida, que no es otra que la de extraer caudal al exterior para su uso. Existen diferencias notables entre las galerías tunecinas y españolas. La más destacada consiste en el porcentaje total de galerías con caudal en ambos territorios, ya que en Túnez apenas alcanza el 17'6\%, mientras que en la zona analizada en España supone el 70\% de las captaciones. En Túnez la mayor parte de los minados están emplazados en las gobernaciones del Sur, en torno a los oasis tradicionales, pero la perforación de sondeos para el abastecimiento de la población y los oasis de nueva creación, que movilizan los acuíferos subterráneos profundos (los del complejo terminal y del continental intercalar sahariano), ha tenido consecuencias muy negativas sobre el freático, al descender de forma notable el nivel piezométrico. Además la intensa urbanización de estos espacios, ha hecho que la mayor parte de las galerías desaparezcan o se encuentren abandonadas y secas. En el Sur de Túnez sólo el 3\% de los minados continúan derivando caudal al exterior, lo que contrasta con el resto de galerías del país, ya que de las 36 restantes el 52’7\% de las mismas poseen caudal.

En España la pérdida de funcionalidad de las galerías alcanza casi el 30\%. Esta ineficacia hídrica tiene varias causas. Existen razones puramente ambientales como la existencia de periodos prolongados de sequía, el aumento de las temperaturas en el último medio siglo o la falta de capacidad de almacenamiento del subsuelo. Se pueden añadir las derivadas de la 
falta de mantenimiento adecuado, lo que ocasiona el hundimiento o el colapso de algunos sectores de la captación. No obstante, el principal motivo para la pérdida de funcionamiento hídrico de estas galerías es el descenso del nivel freático, a consecuencia de la intensificación del volumen de agua extraída del subsuelo mediante sondeos y pozos profundos.

Las galerías drenantes no deben considerarse como un elemento aislado, descontextualizado del medio con el que se relacionan, ya que siempre están integradas y forman parte de un sistema mayor, que incluye diversos elementos del patrimonio del agua. En cuanto a los usos del agua los principales son el regadío y el abastecimiento, aunque en ocasiones se combinan en una misma captación.

Cuadro 5

CARACTERÍSTICAS DE USO DE LAS GALERIAS DRENANTES CATALOGADAS

\begin{tabular}{|c|c|c|c|c|}
\hline \multirow{2}{*}{ Usos del agua } & \multicolumn{2}{|c|}{$\mathrm{N}^{\mathrm{N}}$} & \multicolumn{2}{c|}{$\%$} \\
\cline { 2 - 5 } & E-SE España & Túnez & E-SE España & Túnez \\
\hline Regadío & 166 & 2 & 55,7 & 1,6 \\
\hline Abastecimiento & 36 & 24 & 12,1 & 19,2 \\
\hline Mixto & 92 & 98 & 30,9 & 78,4 \\
\hline Salinas & 4 & 1 & 1,3 & 0,8 \\
\hline TOTAL & 298 & 125 & 100,0 & 100 \\
\hline
\end{tabular}

Fuente: elaboración propia.

Como se observa en el cuadro 5, en el área oriental y suroriental de la península Ibérica las galerías que poseen como único uso un sistema de regadío asociado representan más del $55 \%$, aunque si contabilizamos aquellas que comparten ese uso con el abastecimiento (mixtas) se alcanza el 86'6\%. En Túnez el $80 \%$ de las galerías posee un sistema de regadío asociado al que abastecen. Aunque esta cifra es similar a la que se produce en las galerías españolas la diferencia estriba en que en Túnez tan solo el 1'6\% de las galerías tienen como uso exclusivo el regadío. En Túnez la práctica totalidad de los minados se emplean como abastecimiento de agua potable, ya que se trata de la función primordial en la obtención de caudal. Existe una gran dependencia de esos recursos hídricos para abastecimiento de la población. Al referirnos al abastecimiento incluimos no sólo el abastecimiento urbano, cuando el agua de la galería se integra en la red de agua potable de alguna población, sino también el abastecimiento humano por medio de alguna fuente, y el abastecimiento ganadero por medio de abrevaderos. En España sólo el $43 \%$ de las galerías se utilizan para abastecimiento.

En las provincias meridionales españolas prácticamente no existen galerías que se utilicen exclusivamente para abastecimiento, ya que en la práctica totalidad de los casos se emplean para el regadío (100\% en Almería, 95\% en Murcia y 91'3\% en Alicante). Si exceptuamos el caso de Teruel, que dispone de dos galerías con un uso mixto, las provincias interiores y la más septentrional (Castellón) se caracterizan por tener un porcentaje notable de minados cuyo único uso es el abastecimiento (en Albacete suponen el 30\% del total, en Castellón el $41 \%$ y en Cuenca el $83 \%$ ). 


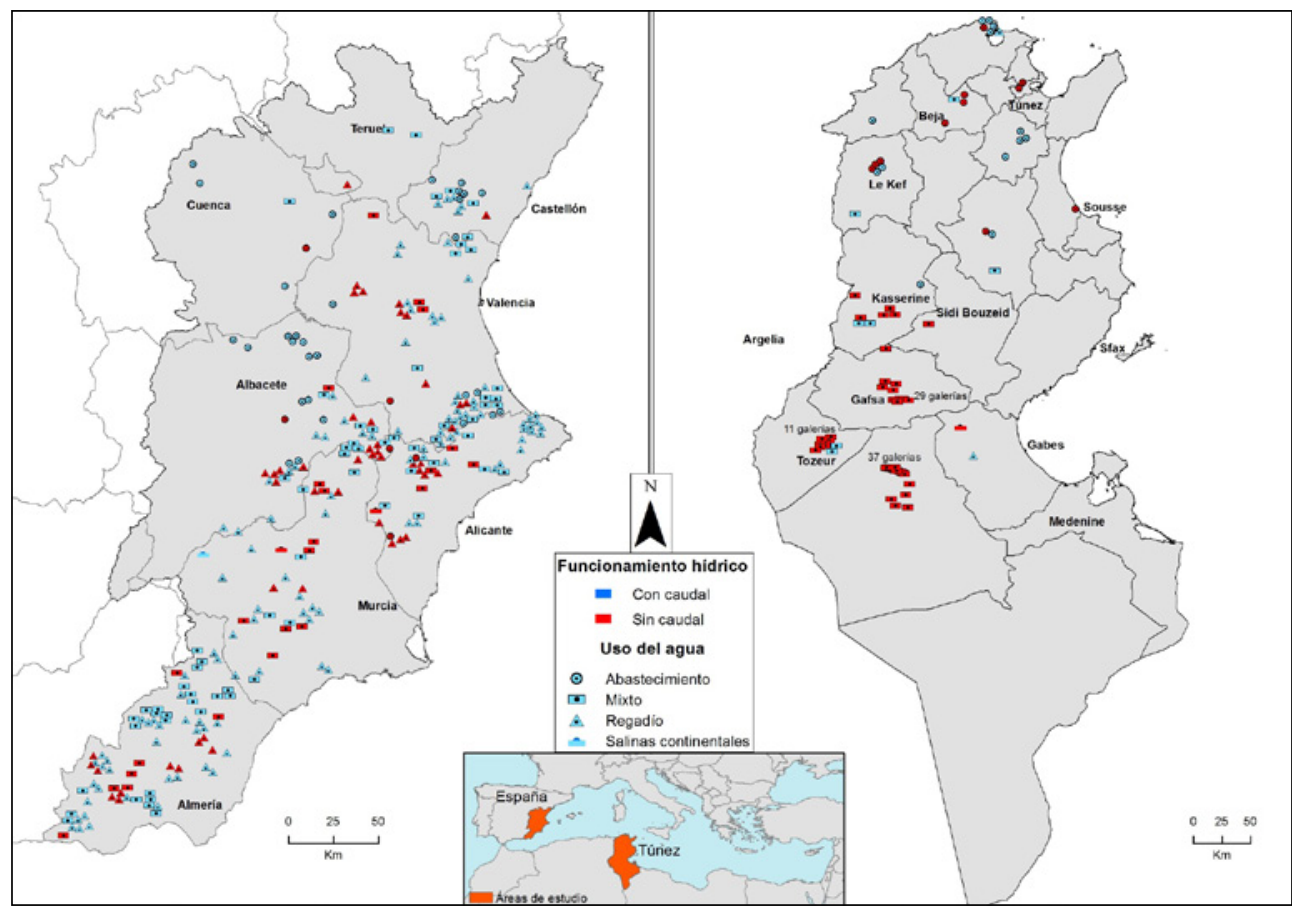

Fuente: elaboración propia.

En Túnez se establece una diferencia muy marcada entre los minados situados en torno a los oasis tradicionales de las gobernaciones meridionales (Kebili, Gafsa, Tozeur y Gabes) y los localizados en el resto del país, ya que el $90 \%$ de las galerías del Sur se empleaban para un uso mixto, mientras que en las restantes ese uso mixto sólo alcanza el 19'4\%, siendo las dedicadas exclusivamente para abastecimiento el 66'6\% y únicamente para regadío el 14\%.

Con un uso más particular hallamos algunas galerías, que permiten la explotación industrial de la sal. Este mineral puede explotarse, o bien con unas salinas continentales como son las de Zacatín en Moratalla (Murcia), las de la Ramona en Calasparra (Murcia) o las de Ain Hdefa en Gabes (Túnez), o bien con un diapiro salino como es el Cabezo de la Sal, en El Pinoso (Alicante).

En el cuadro 6 se cuantifica el número de galerías que poseen un sistema de regadío asociado, en función de su funcionamiento hídrico. En las galerías ubicadas en la Península Ibérica existe una correlación casi perfecta entre las galerías que poseen caudal y la funcionalidad de los regadíos asociados, ya que el 71'7\% de los minados que se utilizan para el regadío poseen caudal y el 29'8\% de los regadíos asociados no se encuentran funcionales. Son varias las causas que provocan el abandono de los regadíos tradicionales en España: la falta de caudal, el elevado minifundismo a causa de un parcelario muy compartimentado, el envejecimiento de los agricultores y la falta de relevo generacional. Además es preocupante 
que exista un $26 \%$ de galerías que poseen caudal, pero cuyo regadío asociado sea complementario o residual. Con esta denominación nos referimos a aquellos riegos en los que permanece en cultivo un porcentaje inferior al $25 \%$ de la superficie regable original, ya que el resto de terrenos a los que abastecía se hallan abandonados. En ocasiones este abandono y desaparición de las zonas regadas se debe al cambio de usos del suelo por la urbanización y la ampliación de infraestructuras. En Túnez, sin embargo, aunque el $91 \%$ de los minados no posean caudal actualmente, los regadíos asociados a las tradicionales galerías drenantes permanecen activos en el $87 \%$ de los casos. Esto es debido a que los espacios alumbrados con el caudal de las galerías permanecen en producción, aunque el agua se obtenga de los pozos y sondeos construidos por la intervención estatal a partir de los años '60 del siglo XX. Estas perforaciones provocaron el agotamiento de las capas freáticas más superficiales, que son las que abastecían a los minados, aunque la captación de nuevos caudales permitió que los oasis se extendieran más allá de los límites que tenían cuando estaban abastecidos por galerías y que, por tanto, aún estén en funcionamiento.

\section{Cuadro 6}

FUNCIONAMIENTO HÍDRICO DE LAS GALERÍAS QUE POSEEN UN SISTEMA DE REGADÍO ASOCIADO

\begin{tabular}{|c|c|c|c|c|}
\hline Modalidades de funcionamiento hídrico y de funcionalidad de los & \multicolumn{2}{|c|}{ España } & \multicolumn{2}{|c|}{ Túnez } \\
\cline { 2 - 5 } sistemas de regadío & $\mathrm{N}^{\circ}$ & $\%$ & $\mathrm{~N}^{\circ}$ & $\%$ \\
\hline Galería con caudal +sistema de regadío funcional & 97 & 37,6 & 7 & 7 \\
\hline Galería con caudal +sistema de regadío no funcional & 21 & 8,1 & 0 & 0 \\
\hline $\begin{array}{c}\text { Galería con caudal +sistema de regadío funcional con un "rol } \\
\text { complementario" }\end{array}$ & 67 & 26 & 2 & 2 \\
\hline Galería sin caudal +sistema de regadío funcional & 17 & 6,6 & 78 & 78 \\
\hline Galería sin caudal +sistema de regadío no funcional & 56 & 21,7 & 13 & 13 \\
\hline TOTAL & 258 & 100 & 100 & 100 \\
\hline
\end{tabular}

Fuente: elaboración propia.

\section{III.4. Estado de conservación}

De las 298 galerías analizadas en España existen 73 (24'5\%) en las que no se ha podido acceder a su interior. Las causas son diversas: a) no localizar al propietario y hallarse el minado cerrado o sellado; b) que el propietario/s no autorice el acceso a su interior; al tratarse de galerías de abastecimiento de agua potable para consumo humano, por lo que el tránsito por su interior podría alterar la limpieza del agua y modificar el grado de turbidez de los caudales; c) la estrechez o escasa altura de la captación, con secciones donde el tránsito por el interior es dificultoso o incluso imposible.

En Túnez hay 2 galerías (1'6\%) en las que no se ha podido acceder a su interior, aunque esa cifra aumenta considerablemente si incluimos aquellas que se encuentran desaparecidas y no quedan vestigios de su existencia (49 ejemplos). La falta de mantenimiento, al hallarse abandonadas, y la urbanización de los terrenos donde se localizaban son las principales causas de su desaparición. 
El estado de conservación de las galerías existentes en ambos espacios analizados es muy diferente. Así como en España el 65’3\% posee un estado de conservación óptimo o excelente, en Túnez sólo suponen el 17'1\%. En España sólo el 13’8\% cuenta con un deficiente estado de conservación, mientras que en Túnez esta cifra alcanza el 28'5\%. En Túnez el 40\% de las galerías han desaparecido, por lo que se han englobado, en el cuadro 7, en la categoría de "muy deficiente". El hecho de que exista un porcentaje tan elevado de galerías desaparecidas se debe al abandono generalizado que sufrieron estas captaciones, a causa del descenso del nivel freático por la implantación de los sondeos promovidos por el estado, lo que ha supuesto su rápida degradación. Hubo una pérdida de interés por parte de las poblaciones locales para la salvaguarda de estos sistemas, al abandonar los trabajos periódicos necesarios para su mantenimiento. La mayoría de galerías desaparecidas se sitúan en los lugares donde se produce un crecimiento urbano generalizado. En los oasis de Souk El Ahad (Kebili), Degueche (Tozeur) o El Guettar (Gafsa) numerosas galerías han desaparecido por debajo de las nuevas edificaciones, lo que periódicamente causa problemas de hundimiento de tierras.

Cuadro 7

ESTADO DE CONSERVACIÓN DE LAS GALERÍAS CATALOGADAS

\begin{tabular}{|c|c|c|c|c|}
\hline \multirow{2}{*}{ Estado conservación } & \multicolumn{2}{|c|}{ España } & \multicolumn{2}{c|}{ Túnez } \\
\cline { 2 - 5 } & $\mathrm{N}^{\mathrm{o}}$ & $\%$ & $\mathrm{~N}^{\mathrm{o}}$ & $\%$ \\
\hline Excelente & 11 & $4^{\prime} 9$ & 5 & $4^{\prime} 1$ \\
\hline Óptimo & 136 & $60^{\prime} 4$ & 16 & 13 \\
\hline Aceptable & 47 & $20^{\prime} 9$ & 18 & $14^{\prime} 6$ \\
\hline Deficiente & 31 & $13^{\prime} 8$ & 35 & $28^{\prime} 5$ \\
\hline Muy deficiente & 0 & 0 & 49 & $39^{\prime} 8$ \\
\hline TOTAL & 225 & 100 & 123 & 100 \\
\hline
\end{tabular}

Fuente: elaboración propia.

El grado de conservación de las galerías suele reflejar el interés social por mantenerlas, con independencia de su valor práctico o estético. En las galerías catalogadas en España se observa, en general, una preocupación por parte de los gestores de las mismas sobre su mantenimiento, sobre todo en aquellos casos en que sigue extrayendo caudal al exterior y se utiliza para abastecimiento o regadío. Es habitual que en las galerías que permanecen activas se realicen de forma periódica tareas de limpieza y mantenimiento, ya que esa es la mejor forma de maximizar los caudales extraídos. En las galerías que presentan un estado de conservación deficiente es frecuente la existencia de derrumbes y desprendimientos, que pueden colapsar su trazado e impedir el tránsito por algunos sectores de la captación.

\section{CONCLUSIONES}

Las galerías drenantes y sus sistemas de regadío asociados están seriamente amenazados. Los regadíos tradicionales sufren actualmente una crisis estructural, lo que repercute en aquellas galerías que les suministran caudal, ya que se producen fenómenos de abandono y 
pérdida de funcionalidad en las mismas. Pese a que la rentabilidad actual de los regadíos tradicionales no está asegurada, este tipo de captaciones de aguas subterráneas poseen un valor patrimonial y paisajístico muy destacado. Las galerías drenantes suelen constituir un modelo de sostenibilidad, una solución inteligente para obtener agua sin esfuerzo, por la fuerza de la gravedad, tras el arduo trabajo inicial que supone su construcción (Pérez Cueva y Antequera, 2006). Las principales amenazas de las galerías son la pérdida de valor de su uso principal y el descenso generalizado de los acuíferos. En este sentido debemos entenderlas como un indicador de "salud ambiental", ya que se aprovechan de los acuíferos subterráneos más superficiales, drenan la capa freática sin sobreexplotar las reservas del acuífero y utilizan las aguas subterráneas como un recurso renovable. A pesar de estas características favorables, en el actual escenario de crisis de las galerías y sus sistemas de regadío y/o abastecimiento asociados, existen diversos tipos de factores que influyen negativamente:

A) Factores climáticos y ambientales: se produce un descenso en los niveles freáticos por el aumento de las temperaturas en los últimos 50 años, al existir una mayor evapotranspiración (IPCC, 2007; Brunet et al., 2007 y 2009). La carencia de recursos hídricos en gran parte de las áreas analizadas supone una fuerte competencia por los usos del agua. Estos factores, junto con los cambios en el balance hídrico e hidrogeológico, pueden provocar el agotamiento hídrico de las galerías.

B) Factores sociales y económicos: existen varias causas que generan un escenario de crisis en las galerías drenantes y los regadíos tradicionales. Los regadíos históricos asociados a galerías tienen una difícil ampliación, al estar condicionados por la línea de rigidez del espacio hidráulico que marca la gravedad. Debido a sus características, las galerías obtienen un caudal reducido en comparación con otros métodos de captación hídrica, ya sean superficiales o subterráneos, por lo que no es factible ampliar su perímetro irrigado. Como consecuencia, y merced a las mejoras tecnológicas en la perforación de pozos y sondeos, se produce una sobreexplotación y el agotamiento de los acuíferos más superficiales (en los oasis tradicionales tunecinos sólo el 3\% de las galerías conservan el funcionamiento hídrico) y, en ocasiones, profundos (cuenca del Vinalopó, en la provincia de Alicante). Otra causa que contribuye a la crisis de los regadíos tradicionales son las actividades humanas, al introducir sustancias contaminantes (fertilizantes químicos, plaguicidas...) y alterar la calidad de las aguas y de los suelos. Los regadíos tradicionales asociados a galerías presentan importantes problemas estructurales, cuya consecuencia es una profunda crisis en las explotaciones agrarias. Existen varios procesos que suponen la inestabilidad de la agricultura como sector económico: la atomización de la propiedad y el minifundismo de las explotaciones agrarias; el envejecimiento de los agricultores y la falta de relevo generacional; la progresiva pérdida de rentabilidad en los regadíos tradicionales; el incremento del precio del suelo; la desaparición de regadíos históricos por cambios en el uso del suelo (urbanización, industrialización, terciarización e infraestructuras); el desarrollo de una agricultura de autoconsumo y subsistencia; y el éxodo rural y la despoblación en las áreas rurales.

C) Factores patrimoniales y paisajísticos: en las últimas décadas se han intensificado los procesos y dinámicas que dan lugar a una depreciación paisajística y patrimonial 
de los sistemas de regadío históricos mediterráneos. Se produce una degradación del Patrimonio Hidráulico. El abandono de las galerías puede provocar su deterioro por falta de mantenimiento y provocar derrumbes y colapsos que impidan la circulación del agua al exterior. La modernización de los regadíos y la sustitución de acequias tradicionales por el riego localizado contribuyen a la degradación del patrimonio hidráulico. Los regadíos abastecidos por galerías drenantes que han sido progresivamente abandonados disponen de una importancia paisajística destacada, muy superior a su trascendencia económica actual. Su abandono supone la desarticulación y fragmentación de los espacios de regadío, con la consiguiente degradación ambiental y la pérdida de las estructuras del paisaje tradicional, lo que produce una disminución estética del paisaje.

D) Factores políticos y de sensibilización ciudadana: tanto en España como en Túnez existe una falta de sensibilidad de las administraciones en lo referente al patrimonio cultural de los regadíos históricos. Su valor cultural, etnológico y paisajístico ha sido menospreciado e incluso, en ocasiones, ignorado. Además se produce una descoordinación entre las diferentes administraciones territoriales y sectoriales, por lo que suele existir un desconocimiento de las actuaciones implementadas en estos organismos. En ninguno de los dos países existe una figura de protección específica e integral sobre el patrimonio hidráulico. Existe una desvinculación evidente entre los ciudadanos y su patrimonio hidráulico, ya que falta una mayor concienciación y sensibilización por parte de la sociedad y de sus representantes. La sociedad muestra un desconocimiento y una falta de interés sobre los sistemas de regadío históricos. Un factor que obstaculiza el conocimiento y la difusión de las galerías drenantes es su difícil patrimonialización, al tratarse de un "patrimonio invisible", ya que es una infraestructura bastante desconocida para la mayor parte de la población.

Aunque entre las galerías del sector oriental y suroriental español y las tunecinas existan algunas diferencias y matices, podemos afirmar que existe un único modelo de crisis en las galerías y en sus sistemas de regadío tradicionales asociados, ya que la mayoría de los factores que la provocan se producen en ambos territorios. Pese a que la situación actual sea de crisis, las galerías son un factor para la creación de paisajes culturales que poseen un elevado valor medioambiental, no sólo por si mismas sino también por el sistema de regadío que generan algunas de ellas. El mejor modo para sustentar y preservar los paisajes culturales que han creado es que permanezcan en funcionamiento y se utilicen para el fin con que fueron diseñadas. Su valor ambiental o cultural puede convertirse en una oportunidad para originar nuevas actividades económicas.

Algunas actuaciones que pueden efectuarse para la protección y puesta en valor son: la instalación de museos o rutas del agua; el establecimiento de figuras de protección (BIC, BRL...) para algunos minados; y la restauración y rehabilitación de galerías. Como ejemplos podemos citar la restauración y puesta en valor de la galería de Ain Bousoufa, en el oasis de El Guettar (Gafsa); la rehabilitación de la Galería del Caño (Cuevas de Almudén, Teruel); y la Ruta del Agua establecida en la rambla de Nogalte (Puerto Lumbreras, Murcia), que incluye la presa subálvea del Caño y Contracaño, su sistema de irrigación y varios de los elementos de su sistema hidráulico. 


\section{REFERENCIAS BIBLIOGRÁFICAS}

AGENCIA ESTATAL DE METEOROLOGÍA (AEMET) (2011): Atlas Climático Ibérico (1971-2000). Ed. Ministerio de Medio Ambiente y Medio rural y Marino; Instituto de Meteorologia de Portugal, $79 \mathrm{pp}$.

ANTEQUERA, M. (2015): Las galerías drenantes en el sector oriental y suroriental de la Península Ibérica. Identificación, análisis y gestión patrimonial. Tesis doctoral, Departament de Geografia, Universitat de València, 1.291 pp.

BARÓN, A. y CARBONERO, M.A. (1987): «Las captaciones por gravedad, qanat(s): Situación actual y posibilidades de uso». En IV Simposio de Hidrogeología, tomo XI, IGME, Palma de Mallorca, pp. 781-795.

BERTRAND, M. y SÁNCHEZ VICIANA, J.R. (2009): «Canalizos y tajeas, dos sistemas de captación de agua mediante galerías subterráneas en las altiplanicies granadinas. Andalucía Oriental». En Arqueología y Territorio Medieval, n 16, pp. 151-178, Universidad de Jaén.

BRUNET, M.; JONES, P. D.; SIGRÓ, J.; SALADIÉ, P.; AGUILAR, E.; MOBERG, A.; DELLA-MARTA, P. M.; LISTER, D.; WALTHER, A. y LÓPEZ, D. (2007): «Temporal and spatial temperature variability and change over Spain during 1850-2005». Journal of Geophysical Research, vol.112, D12117, doi:10.1029/2006JD008249.

BRUNET, M.; CASADO, M.J. y DE CASTRO, M. et al. (2009): Generalización de escenarios regionalizados de cambio climático para España. Ed. Agencia Estatal de Meteorología y Ministerio de Medio Ambiente y Medio Rural y Marino, $158 \mathrm{pp}$.

CASTEJÓN PORCEL, G. (2014): Galerías con lumbreras (Qanats) en Fuente Álamo de Murcia: sistemas históricos de captación y canalización de aguas. Ed. Ayuntamiento de Fuente Álamo de Murcia, 491 pp.

CRESSIER, P. (1989): «Arqueologie des structures hydrauliques en Al-Andalus». En El agua en zonas áridas, arqueología e historia: actas del I Coloquio de Historia y Medio Físico, Almería, 14-15-16 de diciembre de 1989, Instituto de Estudios Almerienses de la Diputación de Almería, Almería, pp. LIII-LXXXVIII.

EL AMAMI, S. (1984): Les Aménagements Hydrauliques Traditionnels de Tunisie (The Traditional Water Planning in Tunisia). Centre de Recherche en Génie Rural, Tunis.

EL FAIZ, M. y RUF, T. (2010): «An introduction to the Khettara in Morocco: two contrasting cases». In: Water and Sustainability in Arid Regions (G. Schneier-Madanes\& M.-F. Courel, eds), Springer Sciencep Business Media.

EL FAIZ, M. (2012): «Enjeux de l'eau et développement durable a Marrakech (Water issues and sustainable development in Marrakech)». En Gómez Espín, J.M. y Hervás AviLÉs, R.M. (Coord.) Patrimonio hidráulico y cultura del agua en el Mediterráneo. Ed. Fundación Séneca; Regional Campus of International Excellence (Campus Mare Nostrum); Agencia Española de Cooperación Internacional para el Desarrollo, pp. 173-178.

GAUCKLER, P. (Dir.) (1897-1912): Enquête sur les installations hydrauliques romaines en Tunisie. Direction des Antiquités et Beaux-Arts, Tunis.

GIL MESEGUER, E. (Coord.) (2007): Sistemas locales de recursos propios de agua en la región de Murcia: Minados y Galerías. Colección Usos del Agua en el Territorio, $\mathrm{n}^{\circ} 4$, Universidad de Murcia, 190 pp. 
GIL MESEGUER, E.; MARTÍNEZ MEDINA, R. y GÓMEZ ESPÍN, J.M. (2011): «Modelos de uso sostenible del agua: las galerías asociadas a presa subálvea». Scripta Nova, Revista Electrónica de Geografía y Ciencias Sociales, Universidad de Barcelona, Vol. $\mathrm{XV}, \mathrm{n}^{\mathrm{o}} 374$.

GIL MESEGUER, E.; GÓMEZ ESPÍN, J.M. y MARTÍNEZ MEDINA, R. (2012): «La investigación en España sobre los sistemas de captación y conducción de pozo horizontal (galería) asociada o no a presa subálvea». En GÓMEZ ESPÍN, J.M. y HERVÁS AVILÉS, R. M. (Coord.): Patrimonio hidráulico y cultura del agua en el Mediterráneo. Ed. Fundación Séneca; Regional Campus of International Excellence "Campus Mare Nostrum"; Agencia Española de Cooperación Internacional para el Desarrollo, pp. 189-202.

GOBLOT, H. (1979): Les Qanats, une technique d'acquisition de l'eau. École des Hautes Études en Sciences Sociales. Ed. Mouton, París.

GÓMEZ ESPÍN, J. M.; GIL MESEGUER, E.; ALIAGA SOLA, I.; LÓPEZ FERNÁNDEZ, J.A. y MARTÍNEZ MEDINA, R. (2007): «Las galerías, construcciones para alumbrar agua de freáticos próximos en el NE de la región de Murcia: minados con espejuelos en Jumilla». Investigaciones Geográficas, $\mathrm{n}^{\circ}$ 42, pp. 89-107.

HENIA, L. (Dir.) (2008): Atlas de l'eau en Tunisie. Unité de Recherche "Grevachot", Faculté des Sciences Humaines et Sociales, Université de Tunis, 186 pp.

HERMOSILLA, J. (Dir.) (2006): Las galerías drenantes del Sureste de la Península Ibérica. Colección Gestión tradicional del agua, patrimonio cultural y sostenibilidad, $\mathrm{N}^{\circ} 1$. Ed. Ministerio de Medio Ambiente, Madrid, 226 pp.

HERMOSILLA, J. (Dir.) (2008): Las galerías drenantes en España. Análisis y selección de qanat $(s)$. Colección Gestión tradicional del agua, patrimonio cultural y sostenibilidad, $\mathrm{n}^{\circ}$ 2. Ed. Ministerio de Medio Ambiente y Medio Rural y Marino, Madrid, 269 pp.

HERMOSILLA, J. (Dir.) (2012): Las galerías de agua en la cuenca hidrográfica del Júcar: un patrimonio hidráulico en el Mediterráneo español. Colección Patrimonio Hidráulico, n ³, 229 pp. Ed. Confederación Hidrográfica del Júcar y Departament de Geografia, Universitat de Valencia.

HERMOSILLA, J. y MOUSSA, M. (Dirs.) (2011): Las galerías de agua tunecinas. Las gobernaciones de Kebili, Tozeur, Gafsa y Gabès. Ed. Departament de Geografia, Universitat de València, 182 pp.

HERMOSILLA, J. y MOUSSA, M. (Dirs.) (2012): Paisaje y galerías de agua en la región centro-oriental de Túnez. Las gobernaciones de Sousse, Monastir, Mahdia, Sfax y Kairouan. Ed. Departament de Geografia, Universitat de València, 252 pp.

HERMOSILLA, J. y MOUSSA, M. (Dirs.) (2013): Las galerías de agua en la región noroccidental de Túnez. Patrimonio hidráulico mediterráneo. Ed. Departament de Geografia, Universitat de València, 308 pp.

IPCC (2007): Cambio climático 2007: Informe de síntesis. Contribución de los Grupos de Trabajo I, II y III al Cuarto Informe de evaluación del Grupo Intergubernamental de Expertos sobre el Cambio Climático. Equipo de redacción principal: PACHAURI, R. K.; REISINGER, A. (Dirs.), IPCC, Ginebra-Suiza, 104 pp.

KOBORI, I. (1976): «Notes on Foggara in the Algerian Sahara». Bulletin of Department of Geography University of Tokyo, vol. 8, pp. 41-55. 
KOBORI, I. (1989): «Comparative studies on the formation of qanat water system». Bulletin of the Institute of the Social Sciencies, vol. 12, $\mathrm{n}^{\circ} 1$, Meiji University.

LAUREANO, P. (2012): «WATER CATCHMENT TUNNELS: QANAT, FOGGARA, FALAJ. AN ECOSYSTEM VISION». EN IWA Specialized Conference on Water\&Wastewater Technologies in Ancient Civilizations, 22-24 March, Istanbul, Turkey.

LIGHTFOOT, D.R. (1997): «Qanats in the Levant: hydraulic technology at the Periphery of Early Empires». Technology and culture, 38 (2), pp. 432-451. Johns Hopkins University Press, Baltimore, Maryland.

MEDGICHE, F.; MOUSSA, M. (2014): «The Qanat as a Crucial Antique Water Acquisition System Common to Arid Zones Communities: Two case Studies, Foggaras in Tunisia and Aflaj in Oman». The International Journal's: Research Journal of Social Science \& Management, vol. 3, n 12, abril 2014.

RON, Z.Y.D. (1995): «Sistema de manantiales y terrazas irrigadas en las montañas mediterráneas». En Agricultura y regadío en Al-Andalus. (II Coloquio de Historia y Medio Físico), Instituto de Estudios Almerienses y Grupo de Investigación Toponimia, Historia y Arqueología del Reino de Granada, Almería, pp. 383-399.

PALERM VIQUEIRA, J. (2004): «Las galerías filtrantes o qanats en México: introducción y tipología de técnicas». En Agricultura, sociedad y desarrollo, vol. I, nº 2, julio-diciembre 2004, pp. 133-145, México.

PÉREZ CUEVA, A.J. y ANTEQUERA, M. (2006): «Contextos ambientales de las galerías drenantes en el Sureste de la Península Ibérica». En HERMOSILLA, J. (Dir.) (2006): Las galerías drenantes del Sureste de la Península Ibérica. Colección Gestión tradicional del agua, patrimonio cultural y sostenibilidad, $\mathrm{n}^{\circ} 1$. Ed. Ministerio de Medio Ambiente, Madrid,pp. 21-41.

SEMSAR YAZDI, A.A.S. y KHANEIKI, M.L. (2010): Veins of desert. A review on the technique of qanat/falaj/karez. Ed. ICQHS (International Center on Qanats \& Historic Hydraulic Structures), 310 pp, Yazd, Irán.

SEMSAR YAZDI, A. A. y KHANEIKI, M.L. (Eds.) (2012): Qanat in its Cradle. Situation of Qanat (Kariz, Karez, Falaj) in the World. Volume 1. Ed. ICQHS (International Center on Qanats \& Historic Hydraulic Structures), 350 pp.

SOLIGNAC (1952): «Recherches sur les installations hydrauliques de Kairouan et des steppes tunisiennes du $\mathrm{VII}^{\mathrm{e}}$ au $\mathrm{XI}^{\mathrm{e}}$ siecle (J.C.)». Annales de l'Institut d'Études Orientales, Tome X. Faculté des Lettres de l'Université d'Alger, 273 pp.

WILKINSON, J. C. (1977): Water and Tribal Settlement in South East Arabia: a study of the Aflâj of Oman, Cambridge University Press, London.

WESSELS, J. (2012): «Groundwater and Qanats in Syria: leadership, ownership, and abandonment». In: Water, Cultural Diversity, and Global Environmental Change (B.R. Johnston et al., Eds). Springer, Netherlands.

YOUNG, A.; YOUNG, D. (1974): Slope Development. Macmillan Education, 35 pp. 
